\title{
El Colegio de México y la política de población en México*
}

\section{Víctor L. Urquidi**}

Empezamos a transitar por una época en que muchas de las conmemoraciones, en este caso de la creación del Consejo Nacional de Población, son reflejo de una etapa nueva de modernización e institucionalización de la vida social y económica de México.

En 1973 se adoptó formalmente, por ley y con apoyo en una reforma constitucional que entró en vigor un poco después, una política de población que, además de reconocer la existencia de una demanda de planificación familiar, enunciaba el compromiso del Estado de atenderla. El Estado y la sociedad civil asumieron de hecho la obligación de vigilar todas las variables que pudieran influir en el número de los habitantes del país, tanto las propiamente demográficas, basadas en la ciencia de la demografia, como las indirectas, de carácter social y económico, urbano y territorial. La población dejó de ser un número cuyo monto creciente se medía por medio de enumeraciones censales; principió a considerarse como un elemento dotado de diversas características -edad, sexo, lugar de nacimiento y de asentamiento, movilidad territorial, estado de salud, nivel de educación alcanzado, ocupación, representación en la familia, capacidad reproductiva y esperanza de vida- interrelacionadas todas ellas con cambios en las estructuras económicas y sociales, con acontecimientos manifestados con diversa intensidad, representada en ciclos no coincidentes, con causas y efectos complejos de mediano y de largo plazos.

En 1964 se había iniciado en El Colegio de México un programa de investigaciones demográficas y estudios de posgrado, teniendo en cuenta valiosos antecedentes aislados y buscando la cooperación y la difusión con otras instancias académicas y con instituciones del sector público, así como con organismos internacionales y medios universitarios de otros países. Se previó dotar a los estudios poblacionales de bases sólidas, en el marco de las tendencias y la problemática del desarrollo económico y social. A la vez, se procuró hallar mediante las

* Palabras del profesor Víctor L. Urquidi en la ceremonia conmemorativa de los 25 años de la creación del Consejo Nacional de Población, celebrada el 25 de marzo de 1999 en la Secretaría de Gobernación.

** Profesor emérito de El Colegio de México. 
investigaciones las características específicas del cambio demográfico de México, sin otorgar a ninguna teoría determinismo alguno.

No me corresponde referirme a los resultados de los programas de El Colegio de México, salvo para poner de relieve que en 1970 se pudo presentar un análisis moderno de la dinámica demográfica de México en los términos antes apuntados, y que dicho estudio fue un antecedente que auxilió al Estado mexicano en la formulación de la nueva política de población, que incluyó el apoyo a la planificación familiar. México llegó así a la Conferencia de las Naciones Unidas convocada en Bucarest en agosto de 1974 con una política de población formulada en el sector público con la colaboración de instituciones académicas, de la profesión médica y del trabajo social, y de diversas otras esferas. En esa conferencia la delegación mexicana desempeñó un papel destacado, sobre todo en la redacción del Plan de Acción para las Naciones Unidas y para los gobiernos participantes en materia de política de población, reconocida ésta ya como elemento central de la convivencia futura de la humanidad. La investigación demográfica previa hecha en México fue valiosa, así como la aplicación de sus resultados, como lo fue la comunicación interdisciplinaria que constituyó el eje metodológico del trabajo realizado entre médicos, economistas, funcionarios y representantes del sector privado, además de los demógrafos.

La creación del Consejo Nacional de Población institucionalizó la política de población y contribuyó al seguimiento de sus resultados, a la evaluación de los programas públicos y privados, y más recientemente, al avance en el conocimiento de los cambios poblacionales, así como al mejoramiento de la información de base. A su vez, los estudios de demografia en El Colegio de México se han profesionalizado cada vez más y se han extendido a otras instituciones universitarias en la capital y en las entidades federativas; cabe señalar que gozan de amplio reconocimiento internacional. La lista de publicaciones sobre temas demográficos es ya larga, y la cooperación entre las esferas académicas de México y las de otros países se ha intensificado.

La problemática demográfica de México continúa presentando desafios de orden social y económico. Pocos paises han experimentado las fuertes migraciones internas que se han registrado entre las áreas rurales y urbanas de México, con amplios alcances territoriales, incluso hacia el exterior del país; pocos países se han urbanizado con la velocidad de las ciudades grandes y medianas de México, rebasando la capacidad de éstas para dotar a sus habitantes de los servicios 
necesarios; en pocos países se percibe el efecto demográfico en el desempleo y el subempleo con la intensidad con que ocurre en México. Ello resulta de la falta de dinamismo adecuado de la economía mexicana en relación con las estructuras demográficas, lo mismo que de la insuficiencia de los programas de planificación familiar que la población demanda a la luz de los diversos factores que inducen a la familia a limitar el número de sus hijos, a posponer el primer embarazo y a abrir intervalos más largos en la procreación, asumiendo responsabilidades familiares plenas, evitando nuevas enfermedades y asegurando la salud de las generaciones jóvenes y las venideras.

En el siglo cuyo arribo ya vislumbramos, no serán los números o las tasas de crecimiento de la población, o su velocidad migratoria, lo que debiera servir como punto de referencia, sino la posibilidad de dotar a la población que resulte de la interacción de las variables demográficas, de las condiciones de calidad de vida y de las oportunidades de mejoramiento económico que debe merecer a lo largo de las próximas generaciones. Este objetivo sería parte de una estrategia de desarrollo sustentable que tenga en cuenta la conservación de los recursos naturales, la instalación de tecnologías y hábitos que eviten las contaminaciones rurales y urbanas, y el aseguramiento del acceso a información, a recursos, a servicios de capacitación y de gestión, a posibilidades reales de empleo y mejoramiento social. Todo ello podrá redundar a su vez en indicadores de la progresión demográfica más acordes con las esperanzas de la población misma.

No creo que la planificación familiar -como instrumento para que las parejas tomen sus propias decisiones sobre el número y espaciamiento de sus hijos, derecho que consigna la Constitución- deba ser un elemento de controversia en una política de población. Si existe demanda de servicios de planificación familiar, la sociedad debe hacer frente a ella con todos los instrumentos necesarios, con plena libertad de elección. En el sector público se requiere todavía mucha más cooperación de la que se practica, y entre el sector público y el privado, con la sociedad civil misma, se necesita todavía mejor comunicación y más apertura de oportunidades, con el respaldo de las instancias médicas, sociales y económicas que hagan posible ejercer este derecho social. 